\title{
Numerical Investigation of Spatial Effects on the Silicon Solar Cell
}

\author{
A.B. Nawale ${ }^{1}$, R.A. Kalal ${ }^{1}$, A.R. Chavan², T.D. Dongale ${ }^{2}$, R.K. Kamat ${ }^{1}$ \\ ${ }^{1}$ Embedded System and VLSI Research Laboratory, Department of Electronics, \\ Shivaji University, 416004 Kolhapur, India \\ 2 Computational Electronics and Nanoscience Research Laboratory, \\ School of Nanoscience and Biotechnology, Shivaji University, 416004 Kolhapur, India
}

(Received 07 January 2016; published online 21 June 2016)

\begin{abstract}
Investigating the effect of device dimension on the silicon solar cell, by using the PC1D numerical simulation environment, we report strong correlation of efficiency of the silicon solar cell with its size. The results showcase finer efficiency at the lower n-type thickness and higher $p$-type thickness. The internal quantum efficiency (IQE) and external quantum efficiency (EQE) too exhibit variation with the device size. As a whole, based on the statistical analysis, especially regression, variance, and best subsets selection, the paper depicts that the $p$-type thickness, ISC and VOC are the preeminent parameters to model the silicon solar cell.
\end{abstract}

Keywords: Silicon solar cell, Numerical simulation, Statistical analysis.

\section{INTRODUCTION}

Solar Energy owing to its non-polluting nature, abundant availability that too at no cost, has undisputedly emerged at the forefront of the non-conventional energy sources. Solar cells albeit their efficiency and cost issues have established themselves as the means to tap the solar energy. Therefore it is quite but natural that researchers all over the globe have been striving hard to come out with high efficiency, cost effective solar cells enduring their life span significantly over extended time period. Interdisciplinary research work is being cultivated in the domains of new materials, novel designs, and reliable fabrication techniques to make up good efficient solar cells. Two most paramount metrics i.e. efficiency and reliability have clearly been seen exceptional in case of crystalline solar cells.

Recently, Panasonic Corporation reported efficiency of the order of $25.6 \%$ for HIT solar cell [1]. Taguchi et al report a little improved efficiency of $24.7 \%$ for silicon wafer based HIT solar cells. [2]. The efficiency of solar cell draws on variety of factors such as, device geometry, material used for the fabrication, internal device dynamics, backend electronics modules etc. In particular, contacts play an important role in efficiency as pointed out by Hilali, et al. by investigating the effect of Ag contacts on silicon solar cell [3]. Internal device dynamics such as plasmonic effects excessively plays a decisive role in efficiency issues as revealed by Winans et al in case of ultrathin amorphous silicon solar cells. Their results confirm that the doping with Ag NPs to silicon solar cell results in significant makeover in the overall performance [4]. Further it has also become increasingly apparent that the other dopents such as $\mathrm{Au}$ NPs as well increase the efficiency of amorphoussilicon solar cells as portrayed by Islam, et al. [5]. With a more substantive and comprehensive exploration Chen et al report the efficiency enhancement due to metal-enhanced nanophosphor fluorescence in case of silicon solar cells [6]. While Qiu, et al. captured the effects of hydrogenation of thin film polycrystalline silicon thereby establishing the direct correlation of performance enhancement with the elevated hydrogen content into the pc-Si layer [7]. Wiesendanger et al has made a unique contribution in understanding the broad sweep of efficiency of the amorphous silicon solar cells with respect to conformal growth mode and isotropic growth mode. Their results revels that the, later leads to improved performance for small lateral correlation length whereas the former shows the same for larger lateral correlation length [8]. Baek et al have established the effect of core quantum-dot size on power-conversionefficiency [9], while Shu et al have thoroughly investigated the effect of interface and doped $a$-Si : H layer defects on performance of silicon solar cell [10].

Armed with the research scenario presented briefly so far in this paper, we have zeroed down on investigating a crucially vital efficiency deciding factor i.e. dimensions of the device. We resort to the PC1D numerical simulation program for the said explorations [11]. The numerical program exploits two-carrier semiclassical semiconductor transport equations, derived basically from the Boltzmann transport equations [1112]. The paper is divided in various sections. Based on the literature survey we open with a brief overview of the connotation of efficiency with the device size. The focus then shifts to the investigations in the simulation environment thereafter concluding the investigations.

\section{DETAILS OF SIMULATIONS}

Simulations have been proved to be very useful in good number of domains such as science, engineering and technology. Simulations, as a third path to knowledge along with theory and experimentation, have become ubiquitous in science, engineering and technology [13-16]. A complete new paradigm in device making in the form of computer assisted combinatorial chemistry is now being endeavored by materials scientist for optimizing the end device features envisaged much before their realization. Working on the same theme, the present simulations carried out using the PC1D numerical simulation program [11] aims at efficiency improvement by modulating the device dimen- 
sions in virtual environment. The PC1D simulation program is based on the two-carrier semiclassical semiconductor transport equations, which are derived from the Boltzmann transport equations [11-12]. The temperature is assumed to be uniform for entire device structure and effect of magnetic fields is neglected [17]. To evaluate the Boltzmann transport equations following assumptions are taken into consideration: (i) the flow of electron and hole carriers are independent; (ii) the population of carriers are in the thermal equilibrium with the surrounding crystal lattice; (iii) the movement of carriers is same for all direction; (iv) energy levels corresponds to electron does not affected by excitation [17].

In the present numerical program photogeneration model comprising of light trapping and free-carrier absorption methods are of particular relevance [17]. In order to probe the effect of device dimensions, we have varied the thickness of $n$-type material as $2 \mu \mathrm{m}, 4 \mu \mathrm{m}$, $6 \mu \mathrm{m}, 8 \mu \mathrm{m}$, and $10 \mu \mathrm{m}$. For each $n$-type dimension, $p$-type material thickness is varied correspondingly as $100 \mu \mathrm{m}, 200 \mu \mathrm{m}$, and $300 \mu \mathrm{m}$. Other simulation parameters are as follows: doping concentration for $n$-type $=1 \times 10^{19} \mathrm{~cm}^{-3}$, and for $p$-type $=1 \times 10^{16} \mathrm{~cm}^{-3}$, exterior front reflectance is fixed as $5 \%$ to all structure, base contact $-0.05 \Omega$ to all device structures, device area $-100 \mathrm{~mm}^{2}$, band gap $-1.124 \mathrm{eV}$, bulk recombina- tion $-\tau_{n}=\tau_{p}=1000 \mu \mathrm{s}, \quad$ illumination intensity $0.1 \mathrm{~W} / \mathrm{cm}^{2}$. For the present investigation surface texturing, surface charge, and exterior front reflectance are not taken into consideration as they are of secondary concern.

\section{RESULTS AND DISCUSSIONS}

The effect of variation in the $p$-type and $n$-type thickness on various parameters of the silicon solar cell is summarized in Table 1. The result trends an inverse relation between the efficiency of silicon solar with the $n$-type thickness which has been gradually varied from $2 \mu \mathrm{m}$ to $10 \mu \mathrm{m}$. The fallout also suggests that the higher efficiency is achieved at the lower value of $n$-type thickness with higher $p$-type thickness. In this case, higher efficiency of the order of $0.211 \%$ is obtained at the $n$-type thickness of $2 \mu \mathrm{m}$ and $p$-type thickness of $300 \mu \mathrm{m}$. Fig. 1 shows the effect of variation in $p$-type thickness at the $n$-type thickness of $2 \mu \mathrm{m}$ on the I-V characteristics of silicon solar cell. The results exemplify that the fill factor and short circuit current becomes higher as the $p$-type thickness increases from $100 \mu \mathrm{m}$ to $300 \mu \mathrm{m}$. This is attributed to the more generation and collection of lightgenerated carriers at the higher value of $p$-type thickness.

Table 1 - Simulation results of silicon solar cell

\begin{tabular}{|c|c|c|c|c|c|}
\hline $\begin{array}{l}p \text {-type thick- } \\
\text { ness }(\mu \mathrm{m})\end{array}$ & $\begin{array}{l}n \text {-type thick- } \\
\text { ness }(\mu \mathrm{m})\end{array}$ & $\begin{array}{lr}\text { Short } \quad \text { Circuit } \\
\text { Current }-I_{\mathrm{SC}}(\mathrm{A}) \\
\end{array}$ & $\begin{array}{l}\text { Open } \quad \text { Circuit } \\
\text { Voltage }-V_{\mathrm{OC}}(\mathrm{V}) \\
\end{array}$ & $\begin{array}{ll}\text { Fill Factor - } \\
\text { FF }\end{array}$ & $\begin{array}{l}\text { Efficiency - } \\
\eta(\%)\end{array}$ \\
\hline 100 & \multirow{3}{*}{2} & 0.0347 & 0.6964 & 0.824 & 0.199 \\
\hline 200 & & 0.0361 & 0.6936 & 0.8043 & 0.201 \\
\hline 300 & & 0.0367 & 0.6906 & 0.8364 & 0.211 \\
\hline 100 & \multirow{3}{*}{4} & 0.0305 & 0.681 & 0.7964 & 0.165 \\
\hline 200 & & 0.0318 & 0.6795 & 0.8376 & 0.181 \\
\hline 300 & & 0.0325 & 0.6775 & 0.8301 & 0.182 \\
\hline 100 & \multirow{3}{*}{6} & 0.0252 & 0.6715 & 0.7916 & 0.133 \\
\hline 200 & & 0.0266 & 0.6706 & 0.833 & 0.148 \\
\hline 300 & & 0.0272 & 0.6689 & 0.8267 & 0.150 \\
\hline 100 & \multirow{3}{*}{8} & 0.0205 & 0.6642 & 0.8355 & 0.113 \\
\hline 200 & & 0.0218 & 0.6637 & 0.8252 & 0.119 \\
\hline 300 & & 0.0224 & 0.6623 & 0.8149 & 0.120 \\
\hline 100 & \multirow{3}{*}{10} & 0.0167 & 0.6581 & 0.8139 & 0.089 \\
\hline 200 & & 0.018 & 0.6579 & 0.7868 & 0.093 \\
\hline 300 & & 0.0186 & 0.6567 & 0.7715 & 0.094 \\
\hline
\end{tabular}

Fig. 2 presents the effect of the variation in the device dimension on internal quantum efficiency (IQE) and external quantum efficiency (EQE). The results reveal that the IQE and EQE are higher at the lower n-type thickness with higher $p$-type thickness and decreases as the $n$-type thickness increases. The decrease in the IQE is attributed to the enhanced recombination effects at higher value of $n$-type thickness. Particularly in the present investigation, IQE and EQE are higher at the $n$-type thickness of $2 \mu \mathrm{m}$ and $p$-type thickness of $300 \mu \mathrm{m}$. It is also observed the EQE is lower than IQE for all the cases. The EQE decreases as the $n$-type thickness increases form $2 \mu \mathrm{m}$ to $10 \mu \mathrm{m}$. The decrease in the EQE is due to fact that the transmission and reflection losses are more at the higher value of $n$-type thickness.

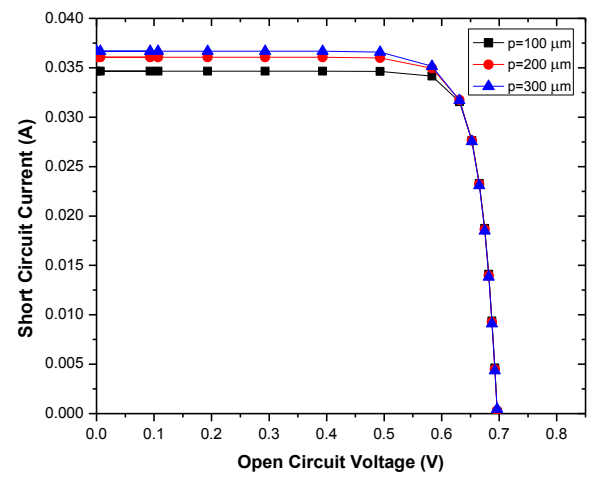

Fig. 1 - Effect of variation in the $p$-type thickness on the I-V characteristics of $\mathrm{Si}$ solar cell at $n$-type thickness equals to $2 \mu \mathrm{m}$ 

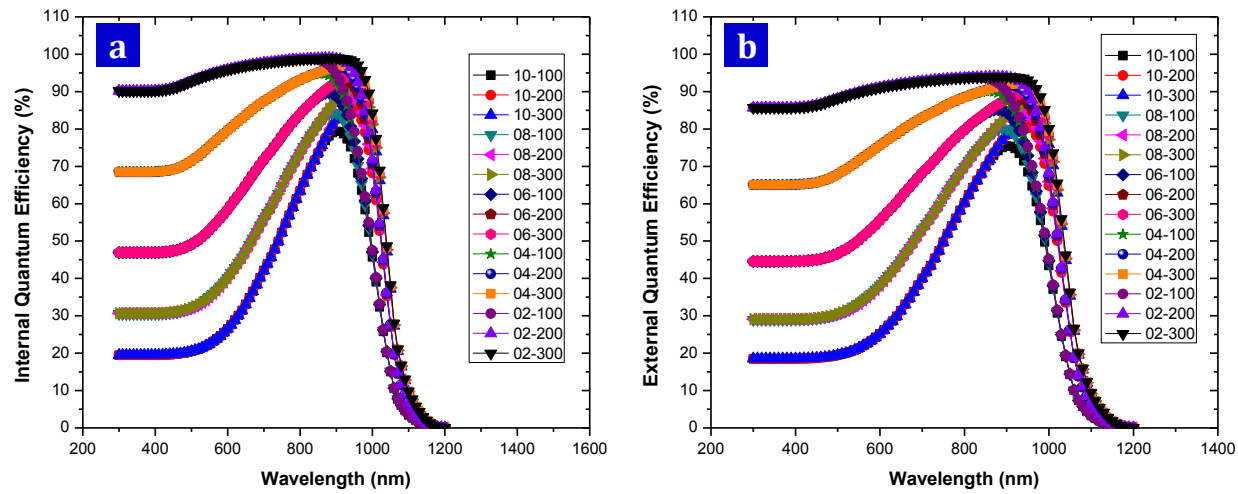

Fig. 2 - Effect of variation in the device dimension on internal quantum efficiency (IQE) and external quantum efficiency (EQE)

We also evaluated effect of variation in the device dimension on the efficiency of silicon solar cell. The results as depicted in Fig. 3 indicate substantial decline in the efficiency of silicon solar cell is with increase in the thickness of $n$-type material gradually from $2 \mu \mathrm{m}$ to $10 \mu \mathrm{m}$. Overall the results demonstrate that the silicon solar cell possess higher efficiency at the lower thickness of $n$-type of material. The results also evidence, the dependence of efficiency of the silicon solar cell on the thickness of $p$-type material and establishes the fact that higher efficiency is achievable at the higher thickness of $p$-type region.

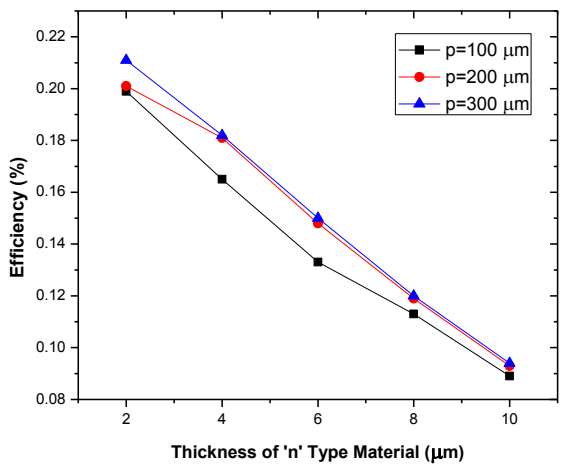

Fig. 3 - Effect of variation in the device dimension on the efficiency of silicon solar cell
Since the complex intrinsic variability of the solar cells is possible with the data driven analysis, we applied selected statistical techniques such as multiple regression, analysis of variance, and best subsets selection in multiple linear regression model. The said statistical analysis intends to analyse the effect of thickness of p-type and $n$-type material, VOC, and ISC on the efficiency of solar cell. From the simulation data the multiple linear regression equation of efficiency can be written as,

Efficiency $(\%)=-0.083+0.000012 p-T H-$ $-0.00194 n-T H-1+4.97 I_{\mathrm{SC}}+0.159 V_{\mathrm{OC}}$

where, $p$-Th represents the thickness of $p$-type material and $n-T H$ represents the thickness of $n$-type of material. From the equation (1), it is easy to predict the efficiency of silicon solar cell for different values of regressor variables. To test for the significance of above regression model, the analysis of variance is calculated and summarized in the Table 2.

The significance value ( $p$-value) of above ANOVA Table 2 comes out to be less than 0.05. This suggests that the p-type thickness, $n$-type thickness, short circuit current-ISC and open circuit voltage-VOC has significant effect on the efficiency- $\eta$. In order to find out maximum effective parameter, we perform best subsets selection in regression analysis, which is summarized in the Table 3. From the Table 3, it is clear that the best

Table 2 - Analysis of Variance

\begin{tabular}{|c|c|c|c|c|c|}
\hline Source of variation & $\begin{array}{c}\text { Degrees of } \\
\text { Freedom }\end{array}$ & $\begin{array}{c}\text { Sum of } \\
\text { Squares }\end{array}$ & $\begin{array}{c}\text { Mean Sum of } \\
\text { squares }\end{array}$ & F-statistic & P-value \\
\hline Regression & 4 & 0.0242525 & 0.0060631 & 469.13 & 0.000 \\
\hline Residual Error & 10 & 0.0001292 & 0.0000129 & & \\
\hline Total & 14 & 0.0243817 & & & \\
\hline
\end{tabular}

Table 3 - Best Subsets Selection in Regression

\begin{tabular}{|c|c|c|c|c|c|c|c|c|}
\hline $\mathrm{P}$ & $\mathrm{R}-\mathrm{Sq}$ & $\begin{array}{c}\mathrm{R} \text {-sq } \\
(\mathrm{adj})\end{array}$ & $\begin{array}{c}\text { Mallows } \\
C_{p}\end{array}$ & $\begin{array}{c}\text { Square root } \\
\text { of MSE }\end{array}$ & $\begin{array}{c}\text { Thickness of } \\
p \text {-type Material }\end{array}$ & $\begin{array}{c}\text { Thickness of } \\
n \text {-type Material }\end{array}$ & $I_{\mathrm{SC}}$ & $V_{\mathrm{OC}}$ \\
\hline 1 & 99.5 & 99.4 & -0.7 & 0.003203 & & & $\mathrm{X}$ & \\
\hline 1 & 97.8 & 97.7 & 29.6 & 0.006352 & & $\mathrm{X}$ & & \\
\hline 2 & 99.5 & 99.4 & 1.2 & 0.003308 & & $\mathrm{X}$ & $\mathrm{X}$ \\
\hline 2 & 99.5 & 99.4 & 1.2 & 0.003319 & & $\mathrm{X}$ & \\
\hline 3 & 99.5 & 99.3 & 3.1 & 0.003447 & $\mathrm{X}$ & $\mathrm{X}$ & $\mathrm{X}$ \\
\hline 3 & 99.5 & 99.3 & 3.2 & 0.003455 & & $\mathrm{X}$ & $\mathrm{X}$ & $\mathrm{X}$ \\
\hline 4 & 99.5 & 99.3 & 5 & 0.003595 & $\mathrm{X}$ & $\mathrm{X}$ & $\mathrm{X}$ & $\mathrm{X}$ \\
\hline
\end{tabular}


subset of regressors for predicting response variable efficiency is $p$-type thickness, $I_{\mathrm{SC}}$ and $V_{\mathrm{OC}}$ due to minimum $C \_p \cong p(3.1 \cong 3)$ i.e. the regression model based on above three regressors is best fit as compared to the other regressors models present in the dataset.

\section{CONCLUSION}

The present manuscript reports the effect of device dimensions on silicon solar cell. The results suggested that the higher efficiency is achieved at the lower value of n-type thickness with higher p-type thickness. The IQE and EQE are higher at the lower $n$-type thickness with higher p-type thickness and decreases as the $n$-type thickness increases. The decrease in the IQE and EQE is due to the recombination effects, transmission and reflection losses. The statistical analysis reveals that the p-type thickness, ISC and VOC are the best parameters to model the silicon solar cell. Work is in progress to validate the simulation results by the way of materials synthesis.

\section{REFERENCES}

1. M.A. Green, K. Emery, Y. Hishikawa, W. Warta, E.D. Dunlop, Prog. Photovoltaics Res. Appl. 23 No 1, 1 (2015).

2. M. Taguchi, Y. Ayumu, S. Tohoda, K. Matsuyama, Y. Nakamura, T. Nishiwaki, K. Fujita, E. Maruyama, IEEE J. Photovolt. 4 No 1, 96 (2014).

3. M.M. Hilali, K. Nakayashiki, C. Khadilkar, R.C. Reedy, A. Rohatgi, A. Shaikh, S. Kim, S. Sridharan, J. Electrochem. Soc. 153 No 1, A5 (2006).

4. J.D. Winans, C. Hungerford, K. Shome, L.J. Rothberg, P.M. Fauchet, Opt. Express 23 No 3, A92 (2015).

5. K. Islam, A. Alnuaimi, E. Battal, A.K. Okyay, A. Nayfeh, Sol. Energy. 103, 263 (2014).

6. J.Y. Chen, C.K. Huang, W.B. Hung, K.W. Sun, T.M. Chen, Sol. Energ. Mat. Sol. C 120, 168 (2014).

7. Y. Qiu, O. Kunz, A. Fejfar, M. Ledinský, B.T. Chan, I. Gordon, D. Gestel, S. Venkatachalm, R. Egan, Sol. Energ. Mat. Sol. C 122, 31 (2014).

8. S. Wiesendanger, T. Bischoff, V. Jovanov, D. Knipp, S. Burger, F. Lederer, C. Rockstuhl, Appl. Phys. Lett. 104
No 23, 231103 (2014).

9. S.W. Baek, J.H. Shim, H.M. Seung, G.S. Lee, J.P. Hong, K.S. Lee, J.G. Park, Nanoscale 6 No 21, 12524 (2014).

10. Z. Shu, U. Das, J. Allen, R. Birkmire, S. Hegedus, Prog. Photovoltaics Res. Appl. 23 No 1, 78 (2015).

11. D. Clugston, P. Basore, Proc. 26th IEEE Photovoltaic Specialists Conf., 207 (1997).

12. P. Basore, IEEE T. Electron. Dev. 37 No 2, 337 (1990)

13. J.E. Froyd, P.C. Wankat, K. Smith, Proc. IEEE. 100, 1344 (2012).

14. T.D. Dongale, S.S. Patil, R.K. Kamat, Int. J. Quality Assurance in Eng. Tech. Edu. 4 No 2, 13 (2015).

15. T.D. Dongale, K.P. Patil, S.R. Vanjare, A.R. Chavan, P.K. Gaikwad, R.K. Kamat, J. Comput. Sci. 11, 82 (2015).

16. T.D. Dongale, P.J. Patil, K.P. Patil, S.B. Mullani, K.V. More, S.D. Delekar, P.K. Gaikwad, R.K. Kamat, J. Nano-Electron. Phys. 7 No 3, 03012 (2015).

17. PC1D User Manual, Available at: http://www.pveducation.org/pvcdrom/characterisation/pc1d. 